\title{
Leonardo y Martin. Por otros quinientos años de vida y fortuna, entre cordura y quimera, de Leonardo da Vinci
}

\author{
María Bendito*
}

El mismo reclamo ansioso que durante el invierno de 2018 me llevó a hacer una interminable cola y a enzarzarme en la lucha por unos pocos minutos frente al Salvator Mundi, penúltima atribución ${ }^{1}$ a Leonardo da Vinci y excéntrica adquisición del Louvre Abu Dhabi, es tan solo un pequeño síntoma de las experiencias que orbitan alrededor de un artista que, desde hace más de quinientos años, hace vibrar el mundo del arte. Descubrimientos, noticias de atribuciones, subastas, disparidad y contrariedad entre los expertos, inauguraciones de altos vuelos, aperturas al público, colas interminables y, al fin, la posibilidad del encuentro frente a frente.

En el Louvre de Jean Nouvel las expectativas eran muy altas y generaban en mí una sensación de imposibilidad que pocas semanas después encontré fielmente descrita de la mano de Martin Kemp en su última publicación sobre Leonardo; obra que, mientras yo me reencontraba con Leonardo en Abu Dhabi, debía de estar de camino a mi habitual librería, como si de una singular sincronía se tratara. Las expectativas nunca se llegaron a cumplir plenamente. La pared que el Louvre emiratí dedicaba a Leonardo da Vinci aún no mostraba el Salvator Mundi -la presentación prevista para el 18 de septiembre de 2018 fue pospuesta a principios del mismo mes sin haber trascendido ningún tipo de aclaración oficial junto con la noticia-, pero no por ello las cabezas, cámaras y móviles cesaban de aglomerarse y participar del espectáculo de La Belle Ferronière (ilustración 1), como si todos los allí presentes, fascinados por el aura de Leonardo, formáramos parte de una coreografía que reproducía el éxito diario de la Gioconda. Felizmente, a la vuelta del viaje, llegaba a mis manos el libro de Martin Kemp.

«Entretenido»e «informativo» son los adjetivos con los que el autor presenta Living with Leonardo. Fifty Years of Sanity and Insanity in the Art World and Beyond, su última referencia a Leonardo da Vinci, publicada por Thames \& Hudson en el mes de marzo de 2018 (ilustración 2). ${ }^{2}$ La edición, de noble calidad — tapa dura y alto gramaje- - formato convencional, desarrolla un relato a lo largo de trescientas veinte páginas acompañadas de noventa cuidadas

1. Al concluir el presente texto se difunde internacionalmente la noticia de la última atribución a Leonardo da Vinci: una mayólica del arcángel Gabriel que, de verificarse su autoría, se convierte en la primera de sus obras documentadas, realizada cuando el artista contaba con tan solo dieciocho años. La atribución la presenta a expertos y medios el profesor Ernesto Solari. Más adelante volveré a esta noticia para contextualizarla con mayor detalle.

2. KemP, M., Living with Leonardo. Fifty Years of Sanity and Insanity in the Art World and Beyond. Londres: Thames \& Hudson, 2018.

* Esta investigación se enmarca en los proyectos de investigación financiados por el Ministerio de Economía y Competitividad: ACAF/ART IV «Cartografías analíticas, críticas y selectivas del entorno artístico y monumental del área mediterránea en la edad moderna» (HAR201566579-P), y CCAV/ ART II

«Cartografía crítica del arte y la visualidad en la Era Global: nuevas metodologías, conceptos y enfoques analíticos» (HAR201343122-P). 


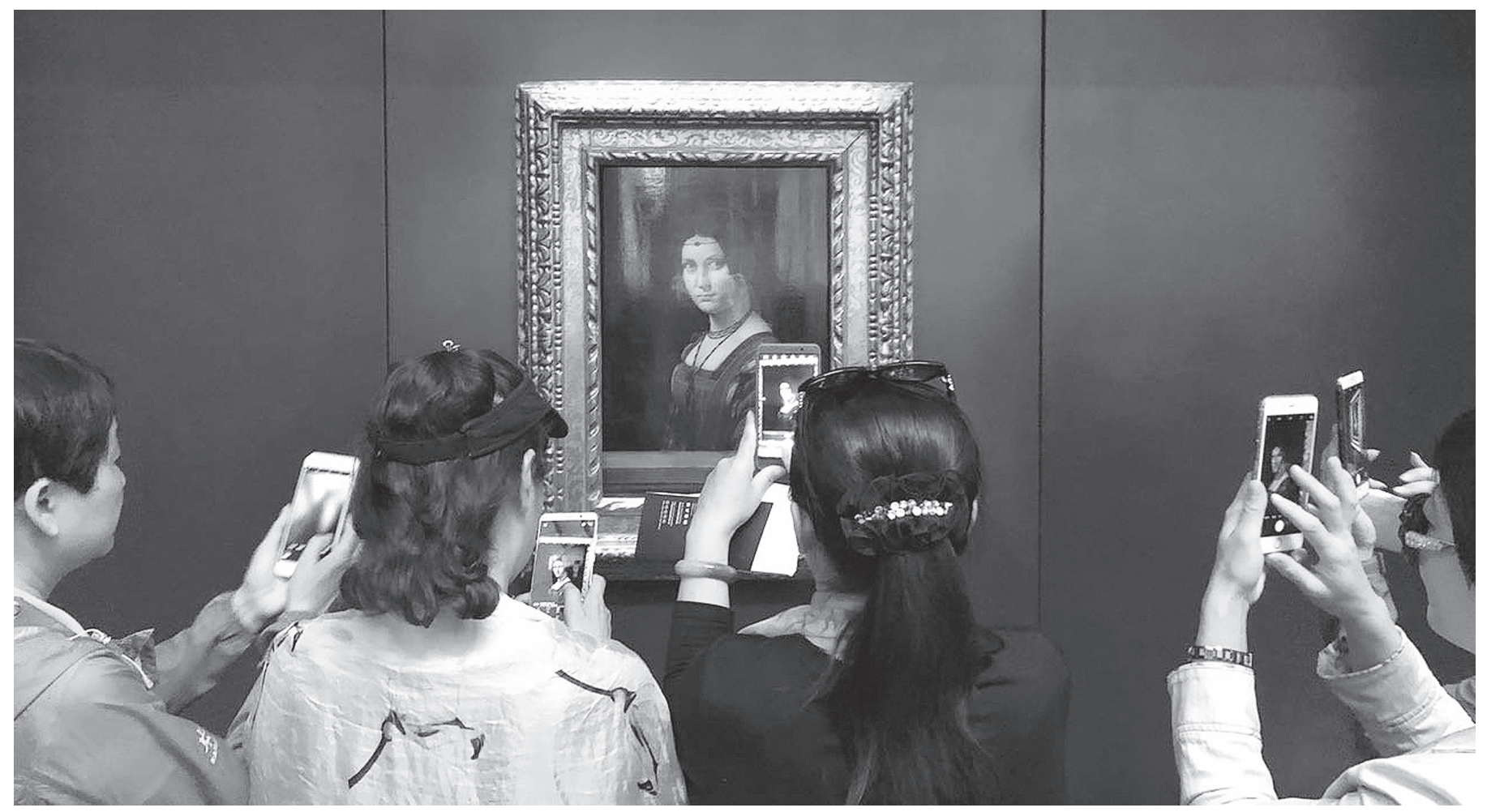

1. Leonardo da Vinci La Belle Ferronière, c. 1490-1495, óleo sobre tabla, $63 \times 45 \mathrm{~cm}$. Musée du Louvre, París (en préstamo provisional en Louvre Abu Dhabi, Abu Dhabi). ilustraciones que el lector apreciará y sin las cuales, en palabras de Kemp, el texto sería mucho más pobre.

El objetivo de la publicación es convertirse en uno más de los acontecimientos que entre 2018 y 2019 conmemorarán a Leonardo da Vinci en el 500. aniversario de su muerte (1519), como las exposiciones del Teylers Museum de Haarlem —Leonardo da Vinci, 5 octubre 2018 - 6 enero 2019 - , la Galleria degli Uffizi - Il Codice Leicester di Leonardo da Vinci. L'Acqua Microscopio della Natura, 30 octubre 2018 - 20 enero 2019-, el Musée du Louvre -Léonard de Vinci, 24 octubre 2019 - 24 febrero 2020-, el Palacio de Buckingham en colaboración con otras sedes Reino Unido -Leonardo da Vinci: A Life in Drawing, 1 febrero - 6 mayo 2019-, y otras muchas actividades, como las del Museo Leonardiano de Vinci y Clos Lucé, entre otras. ${ }^{3}$

El objetivo de Kemp, sin embargo, no es rendir un homenaje tradicional a la figura del artista, sino descubrir al lector el mundo orbital - exposiciones, subastas, robos y no pocos episodios de pugnas narcisistas - que, en los últimos cincuenta años de relación, han sobrellevado el autor, Leonardo da Vinci y las obras de uno y del otro. Como si de una novela policíaca se tratara, el lector es guiado de la mano de Martin Kemp a través de crónicas y personajes que este escoge y que se exponen con una escritura limpia, ágil, amena y crítica a la vez, más propia, en principio, de un exquisito contador de cuentos que de un historiador. Por ello, esta

3. Por ejemplo, en el Museo Leonardiano de Vinci se expondrá el célebre dibujo Estudio de paisaje toscano (1473). El préstamo se acompañará, previsiblemente, de otros importantes documentos del Archivio di Stato di Firenze y la exposición abrirá sus puertas el 15 de abril de 2019, coincidiendo con el aniversario del nacimiento de Leonardo da Vinci. Mientras que el dibujo se expondrá durante las primeras seis semanas, el resto de las obras y documentos permanecerán por seis meses en la Sala del Podestà del Castello dei Conte Guidi de Vinci. El comunicado de prensa se publicó en la página web del museo, Il paesaggio protagonista delle Celebrazioni Leonardiane del 2019, 16 abril 2018, disponible en http:// www.museoleonar diano.it/eng/press-room/press-releases [fecha de consulta: 27 de junio de 2018]. En cuanto a Clos Lucé, se prevé que la celebración del quinto centenario gire en torno al Cenacolo, gracias a la exhibición de un tapiz basado en la escena del refectorio de Santa Maria delle Grazie. La obra, propiedad de la Pinacoteca Vaticana, es de manufactura flamenca y fue donada al papa Clemente VII por Francisco I de Francia en el año 1532. Se podrá visitar en el castillo francés entre el 1 de junio y el 2 de septiembre de 2019 . 


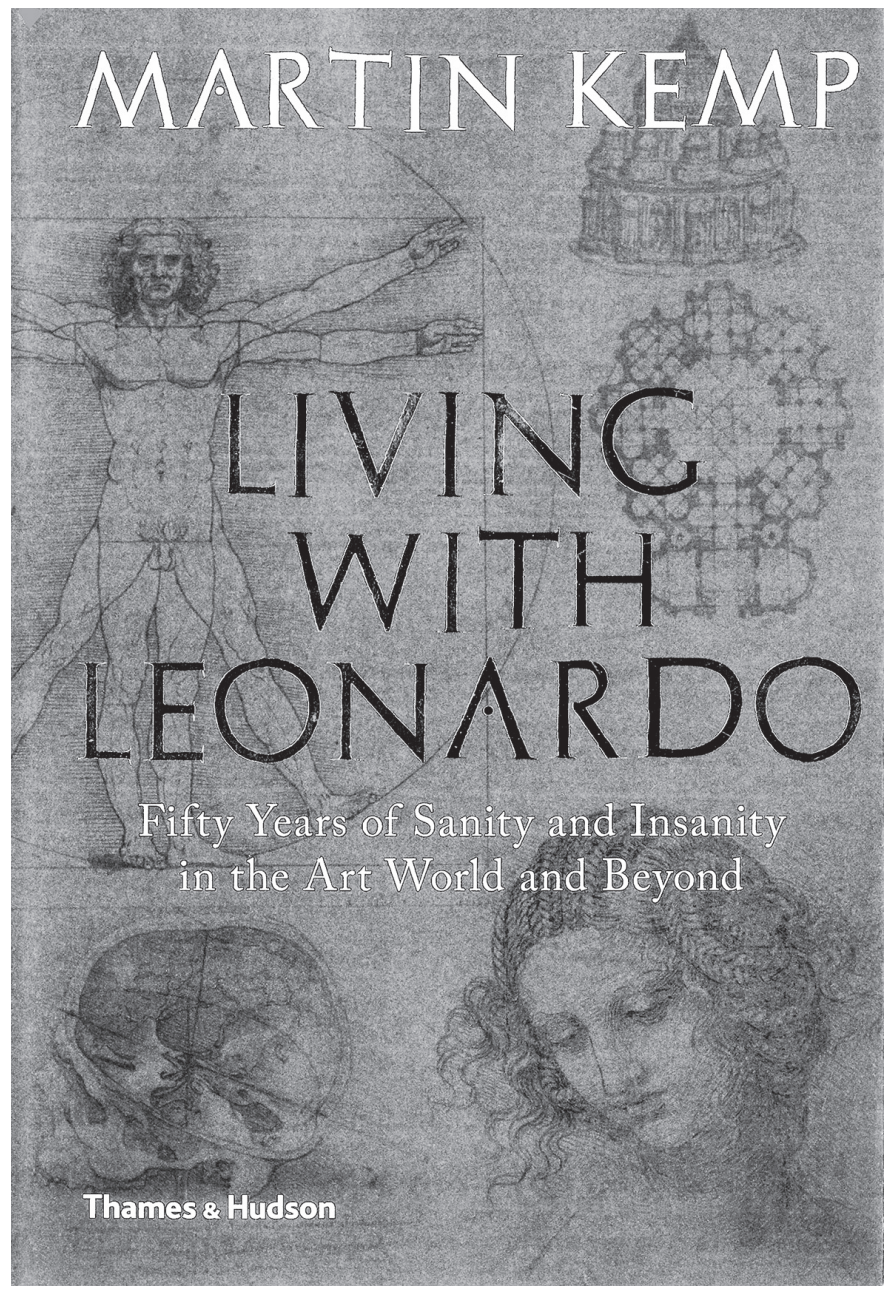

2. Martin Kemp

Living with

Leonardo. Fifty

Years of Sanity

and Insanity in

the Art World

and Beyond.

Londres: Thames

\& Hudson, 2018,

portada.

nueva propuesta difiere diametralmente del tipo de trabajo que realizó en su primera monografía sobre el artista, The Marvelous Works of Nature and Man, publicada en 1981 por Harvard University Press, reeditada numerosas veces y traducida al castellano por Alfredo Brotons $\mathrm{Mu}$ ñoz para la colección Arte y Estética de Akal en 2011 (ilustración 3). ${ }^{4}$

Si existe en el libro alguna hipótesis original es la de que los escenarios que el artista promueve póstumamente - exposiciones, trabajos científicos, novelas, películas e incluso batallas legales- representan un negocio de tal envergadura que es necesario presentarlo, desenmascararlo y criticarlo. Este es el hilo conductor de la propuesta de Kemp. Un claro precursor de este trabajo fue Leonardo \& io de Carlo Pedretti, editado por Mondadori en 2008 y en el que se desarrolla una combinación entre la vida del artista y la del historiador (ilustración 4). ${ }^{5}$ Pedretti presenta también una cronología de medio siglo de relación que, al igual que la del inglés, se hace patente en el subtítulo de la obra. Pero si bien Pedretti expone un nivel de densidad académica, detalle y documentación mucho mayor, carece de la visión sobre las instituciones y personajes circundantes que Kemp ofrece.

4. Kemp, M., The Marvelous Works of Nature and Man. Cambridge (Mass.): Harvard University Press, 1989. En castellano: idem, Leonardo da Vinci: las maravillosas obras de la naturaleza y del hombre. Traducción de Alfredo Brotons Muñoz. Madrid: Akal, 2011.

5. Kemp considera que Pedretti es el mayor conocedor de Leonardo, mientras que el italiano, aun nombrando a Kemp en considerables ocasiones, no le dedica ningún apelativo gratuito sin un previo argumento o contextualización que le lleva en tantas ocasiones al reconocimiento como a la reprobación. Véase PedretTi, C., Leonardo \& io. Milán: Mondadori, 2008. 


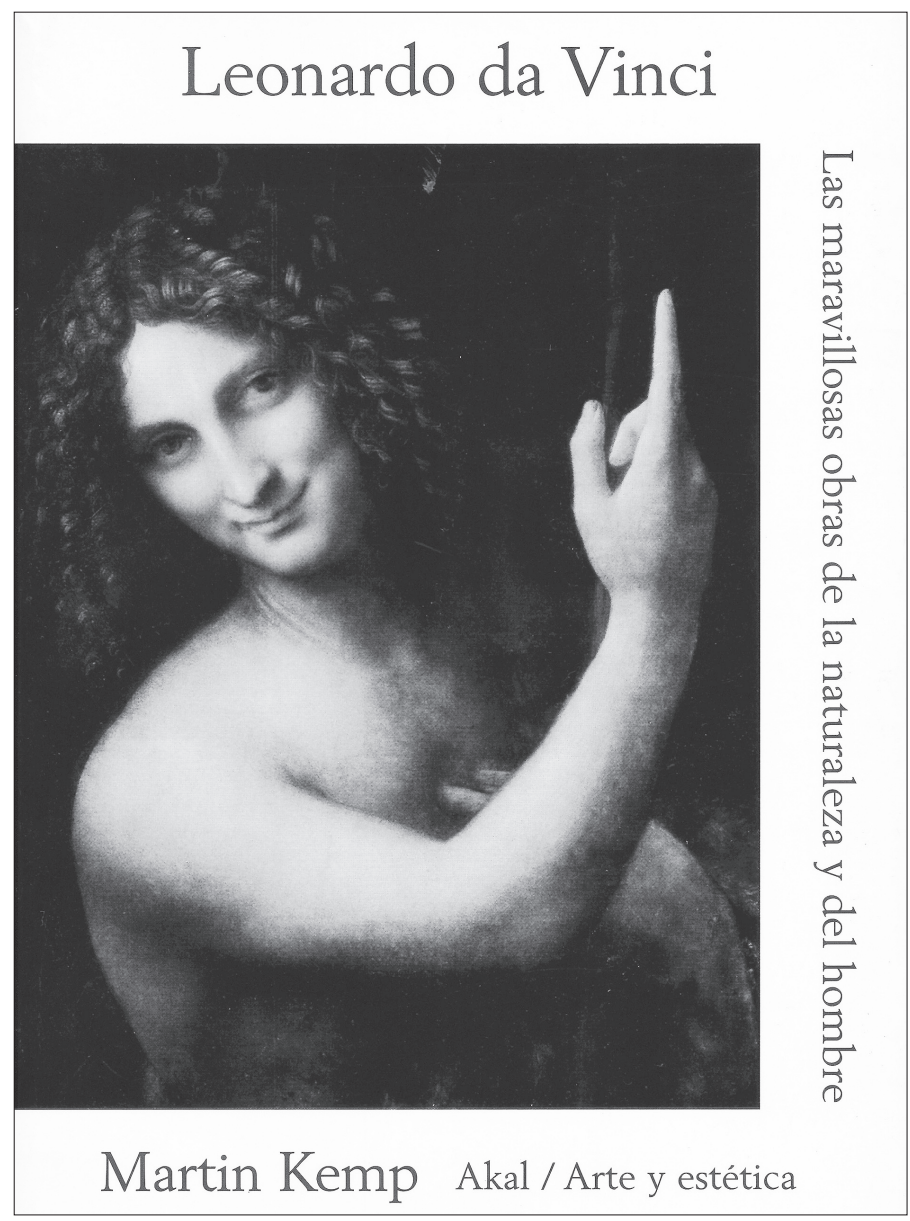

3. Martin Kemp Leonardo da Vinci: las maravillosas obras de la naturaleza $y$ del hombre. Traducción de Alfredo Brotons Muñoz. Madrid: Akal, 2011, portada.

4. Carlo Pedretti Leonardo \& io. Milán:

Mondadori, 2008, portada.

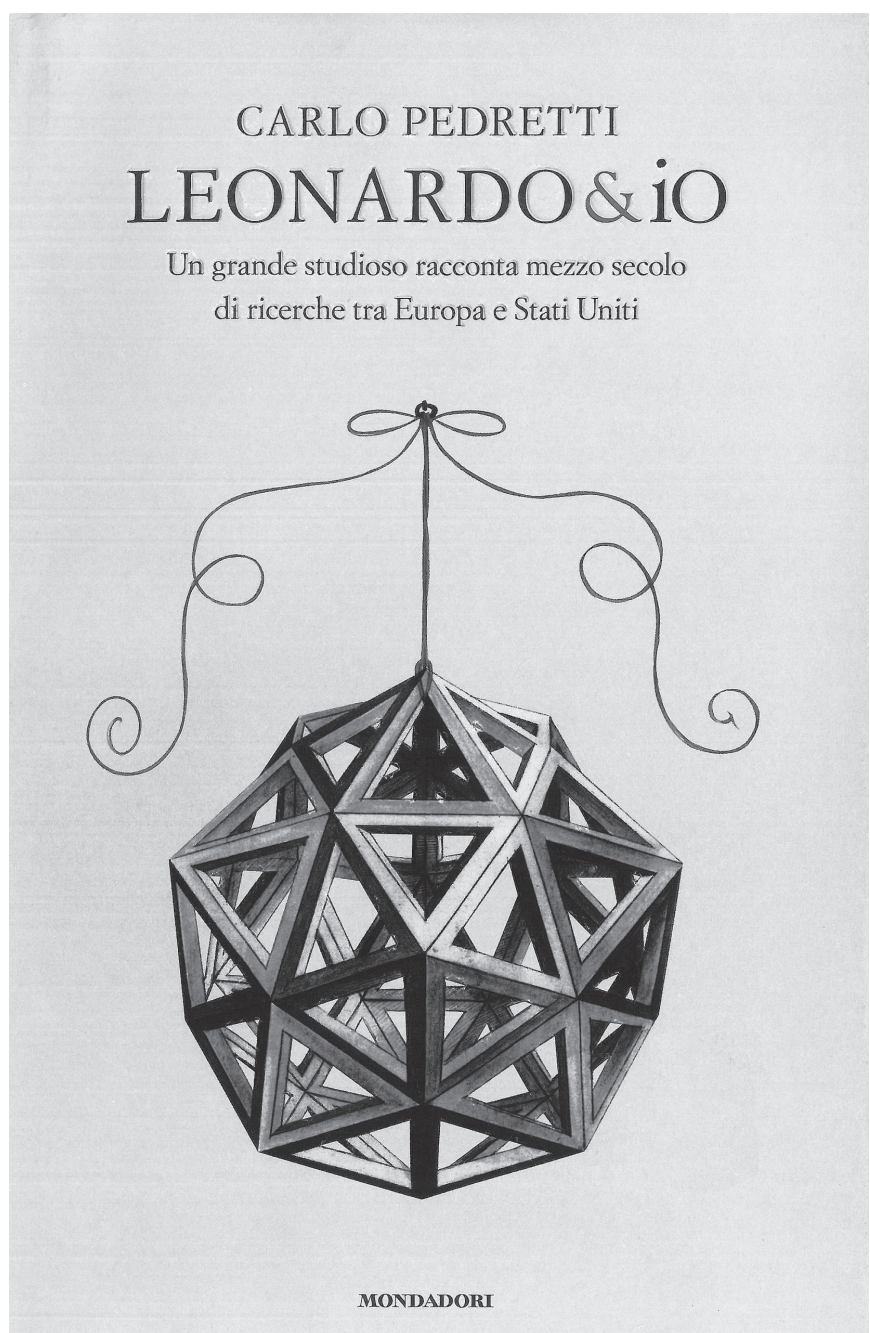

Con la biología como primera formación, Martin Kemp inició su relación con Leonardo da Vinci a través de la serie de dibujos anatómicos de la colección del Castillo de Windsor, gracias al encargo de la BBC de realizar un documental sobre las impresiones del artista renacentista acerca del agua y su movimiento. De su análisis surgió la primera de las hipótesis de su dilatado estudio de Leonardo - el sistema sensorial y el mental como fuerzas motrices detrás de las expresiones y gestos del Cenacolo - y, en consecuencia, las primeras publicaciones científicas: «Il Concetto dell'Anima in Leonardo's Early Skull Studies» (1971), «Dissection and Divinity in Leonardo's Later Anatomies» (1973) y «Leonardo and the Visual Pyramid» (1977). ${ }^{6}$ Los artículos dieron paso al monográfico de 1981 que, por aquel entonces, consideraba que sería la última de sus contribuciones sobre el creador renacentista. Muy equivocado estaba en ese momento: de aquel encuentro se abrió un diálogo de por vida con el artista que, se diría, ahora pretende concluir.?

6. КемР, M., «Il Concetto dell'anima in Leonardo's Early Skull Studies», Journal of the Warburg and Courtauld Institutes, 34, 1971, págs. 115-134; «Dissection and Divinity in Leonardo's Late Anatomies», Journal of the Warburg and Courtauld Institutes, 35, 1972, págs. 200-225; «Leonardo and the Visual Pyramid», Journal of the Warburg and Courtauld Institutes, 40, 1977, págs. 128-149.

7. Al margen del número de publicaciones que Martin Kemp ha realizado sobre la obra y pensamiento de Leonardo da Vinci, ha sido comisario de tres exposiciones monográficas sobre el artista, en las que se apoya a lo largo del presente libro para desarrollar algunos de sus argumentos. Son: Leonardo da Vinci: Artist, Scientist, Inventor, en 1989 en la Hayward Gallery de Londres; Leonardo da Vinci: the mistery of the Madonna of the Yarnwinder, en la National Gallery of Scotland en 1992; y Leonardo da Vinci: Experience, Experiment, Design, en el Victoria \& Albert Museum de Londres en 2006. 
El título escogido, Living with Leonardo. Fifty Years of Sanity and Insanity in the Art World and Beyond, evidencia una cierta intención autobiográfica en la que Kemp, protagonista y agente, expone a un Leonardo que le asiste indirectamente. ${ }^{8}$ La única estructura cronológica se desprende todavía del título, al apuntar que el contenido cubre medio siglo de relación entre los dos personajes. El argumento, en cambio, tiene una ordenación temática, a excepción de un pequeño prólogo, A sketch of Leonardo, cuya función es la de ofrecer una síntesis biográfica y artística de Leonardo en la que se enfatizan los momentos cruciales, las obras más importantes y las relaciones interpersonales que configuraron su obra y carácter. Los primeros siete capítulos se construyen a partir de las anécdotas que las creaciones Cenacolo, Gioconda, Bella Principessa, Madonna dei Fusi y Salvator Mundi han brindado a Martin Kemp. Los últimos cuatro capítulos, por el contrario, muestran los escenarios que emergen de la fortuna de Leonardo da Vinci en cuestiones como el uso de la ciencia, la computarización, las exposiciones y la difamación.

El homenaje de Kemp empieza con el tema del Cenacolo, que ocupa el primer y el segundo capítulo. Mediante una redacción fluida, llena de apreciaciones sensoriales y descripciones físicas y anímicas, el autor es capaz de sintetizar años de experiencias con el Cenacolo en escasas frases sin sacrificar ni un ápice de información o impresiones. No por ser el capítulo inicial se sobrevalora su mérito literario, pero lo cierto es que la calidad y facilidad con la que mezcla sus recuerdos en el aula como estudiante, junto con la inspiración de sus maestros - Kenneth Clark, Ernst H. Gombrich, Anthony Blunt y John Shearman- y ese modo natural de hacerlos presentes en el relato, se va desvaneciendo en los apartados posteriores como si su deseo por esbozar un autorretrato hubiese quedado saciado. Entretanto, el lector ha podido observar cómo en la mente de Kemp existe una unión e intercambio constantes entre ciencia y arte, pasado y presente, estudiante e historiador.

El citado segundo capítulo aprovecha la polémica limpieza del Cenacolo, llevada a cabo entre 1977 y 1999, para presentar la problemática que siempre han suscitado las grandes campañas de restauración en los círculos académicos y los medios de comunicación. ${ }^{9}$ En el Cena-

\footnotetext{
8. Se puede considerar que en el ámbito de la literatura histórica y crítica del arte, la conversión del historiador en protagonista o coprotagonista del relato es un fenómeno recurrente del que son ejemplo los casos de Martin Kemp y Carlo Pedretti. También es un fenómeno habitual el de la conversión del autor en contertulio del creador, cuyo ejemplo histórico paradigmático es el diálogo del humanista Francisco de Holanda con Miguel Ángel. Presente en el Livro segundo da pintura antigua del tratado Da pintura antigua de 1548, fue traducido del original al español por el pintor español de ascendencia portuguesa Manuel Denís en 1565. Se puede consultar la segunda edición —la primera data de 1890-, a cargo de Joaquim de Vasconcellos: Holanda, F. DE., Da pintura antiga. Tratado de Francisco de Hollanda. Oporto: Renascença Portuguesa, 1918, disponible en https://app.box.com/s/3xew6zcukewqehyfnb72 [fecha de consulta: 27 de junio de 2018]. Francisco de Holanda, Carlo Pedretti y Martin Kemp responden a diferentes patrones de posicionamiento del historiador frente al objeto y sujeto de estudio. Mediante tales patrones transmiten una aparente mayor veracidad a través del formato diálogo, o una distancia impersonal y objetiva a través del modelo de la biografía crítica, cuyo arquetipo coetáneo a Francisco de Holanda es Le vite de' più eccellenti pittori, scultori, e architettori de Girogio Vasari publicadas en Florencia por Lorenzo Torrentino en 1550 y, en su segunda edición y con ligeras variaciones de título, por Giunti, igualmente en Florencia y en el año 1568. Entre uno y otro, Pedretti y Kemp se acercan más a la estructura del coloquio, haciendo de exégetas de un artista de rol pasivo en favor de su mayor protagonismo como historiadores. En efecto, a modo de prólogo en Leonardo \& io, Carlo Pedretti emplea la fórmula del diálogo al reproducir una entrevista realizada en 2003; así, marca el tono subjetivo del resto del relato a la vez que realiza el ejercicio de manifestarse a través de la vida y obras del artista, objetivo encubierto en este posicionamiento.

9. En 1975, Pinin Brambrilla Barcilon advirtió que pequeños fragmentos de pintura empezaban a desprenderse del muro del refectorio; dos años más tarde empezaba su campaña de restauración. Los resultados se publicaron en BRAMBILLA BARCILON, P.; Marani, P.C., Leonardo, L'Ultima Cena. Milán: Olivetti-Electa, 1999. En aquel contexto también se emprendieron relevantes restauraciones de otras obras del renacimiento italiano. En Roma, los trabajos de recuperación de los frescos de Miguel Ángel en la Capilla Sixtina se llevaron a cabo entre 1980 y 1990, tras el éxito obtenido en la limpieza de los ciclos de Moisés y Cristo de los muros laterales entre 1964 y 1975, cuando se pudo restablecer su equilibrio cromático. En Florencia, los frescos de Masaccio y Masolino para la Capilla Brancacci, fueron restaurados entre 1984 y 1989, aunque las líneas generales se establecieron ya en 1969. En los casos citados se dirigió la actividad no solo a la recuperación y conservación de las obras, sino también a una investigación más amplia que permitiera resolver problemas históricos de esta práctica pictórica y su conservación. Véase CATHER, S. (ed.), The Conservation of Wall Paintings: proceedings of a symposium organized by the Courtauld Institute of Art and the Getty Conservation Institute, London, July 13-16, 1987. Los Ángeles: The J. Paul Getty Trust, 1991. El volumen contiene los capítulos «Preliminary Research for the Conservation of the Brancacci Chapel, Florence», por Ornella Casazza y Sabino Giovannoni, págs. 13-19; «The Frescoes of Michelangelo on the Vault of the Sistine Chapel:
} 
colo, la restauradora Pinin Brambilla Barcilon y su equipo, no solo lidiaron con la dificultad de restaurar una obra casi completamente arruinada, ${ }^{10}$ sino también con la presencia de cientos de visitantes molestos y la persecución mediática de ArtWatch International, organización que, en pos de las buenas prácticas en la conservación de la obra, tomó partido contrario y se ocupó de manchar la campaña acusando a los implicados de estar encubriendo una transacción publicitaria además de traumatizar la obra de Leonardo."

Un cambio de concepto analítico se produce en el tercer episodio, que narra la presión a la que es sometido el arte por parte del espectador, tomando como caso de estudio la Gioconda. Kemp trasciende la obra para analizar cómo estas expectativas juegan un rol esencial en la creación de los escenarios periféricos: debates sobre originalidad, proliferación de hipótesis —algunas, asumibles; otras, imprudentes - ${ }^{12}$ polémicas perpetuamente abiertas, creación del fenómeno mediático, consiguiente contigüidad del mercado, etcétera.

En el siguiente capítulo de este relato casi detectivesco aparece uno de los temas que no podía faltar en una antología de sucesos: el robo de la Madonna dei fusi atesorada en Escocia, acontecido en agosto de 2003. ${ }^{13}$ Martin Kemp, que se encontraba en la Toscana en el momento de recibir la noticia, orienta elegantemente al lector hacia una confusión de su persona con la de Leonardo, ambos habitantes, admiradores y estudiosos de los mismos paisajes, pero con quinien-

Conservation Methodology, Problems, and Results», Fabrizio Mancinelli, págs. 57-66 y «The Frescoes of Michelangelo on the Vault of the Sistine Chapel: Original Technique and Conservation», de Gianluigi Colalucci, págs. 67-76.

10. Uno de los mayores problemas que afrontar en la restauración del Cenacolo era la falta de una referencia fidedigna y original, a lo que había de sumarse la técnica experimental y poco sólida de Leonardo y contingencias cruciales como la destrucción casi completa del refectorio, como resultado de los bombardeos de las fuerzas angloamericanas en agosto de 1943, y las dos recientes campañas de restauración del conservador del Istituto Centrale del Restauro, Mauro Pellicioli entre 1947 y 1949 - primera consolidación de la pintura- y entre 1952 y 1954 — extracción de añadidos no originales-. Véase Basile, G.; Marabelli, M., Leonardo. L'Ultima Cena. Indagini, ricerche, restauro. Florencia: Nardini, 2007.

11. Aún se continúan refiriendo en los mismos términos en sus publicaciones más recientes. Véase DALEY, M., «The Perpetual Restoration of Leonardo's “Last Supper" - Part 1: The Law of Diminishing Returns», ArtWatch UK Online, 8 de febrero de 2012; del mismo autor: «The Perpetual Restoration of Leonardo's Last Supper, Part 2: A traumatic production of "a different Leonardo" ", ArtWatch UK Online, 14 de marzo de 2012. Ambos artículos se pueden consultar en http://artwatch. org.uk/archive/ [fecha de consulta: 23 de junio de 2018].

12. Entre las asumibles, Kemp considera aquellas llevadas a cabo por estudiosos de forma autónoma y profesional, esto es, que no responden a ningún tipo de patrocinio privado, como la que le llevó a colaborar con el economista florentino Giuseppe Pallanti acerca del entorno y proveniencia de Lisa del Giocondo. La investigación conjunta tuvo como fruto la publicación Kemp, M.; Pallanti, G., Mona Lisa. The People and the Painting. Oxford: Oxford University Press, 2017. Entre las imprudentes se encuentran todas aquellas que, por exponer solo un caso, confabulan en torno a la personalidad de Leonardo da Vinci como pintor de mensajes herméticos. En este ámbito encontramos hipótesis como las presentadas por Silvano Vinceti, responsable del autogestionado Comitato Nazionale per la Valorizzazione dei Beni Storici, Culturali e Ambientali, y detector de un supuesto mensaje oculto en la mirada y el reverso de la Gioconda, además de considerar la obra como un autorretrato del artista. En KeMP, M., «Codes and Codswallop», en idem, Living with Leonardo..., págs. $280-308$.

13. Leonardo trabajó en esta tipología de la Madonna entre 1499 y 1501 en su retorno a Florencia después de dieciocho años en la capital Lombarda, previo paso por Mantua - donde el encuentro con Isabella d'Este produjo el retrato que se encuentra en el Louvre- y la ciudad de Venecia. En Leonardo, el tema del fuso o huso, que desde antiguo estaba asociado al paso del tiempo como metáfora del tejer la vida y la espera de la muerte, se refiere explícitamente a la muerte de Cristo mediante su representación cruciforme. El artista también había desarrollado el concepto del huso en el Codice Atlantico, donde estudió y diseñó máquinas textiles —-fols. 393r y 1050r-, así como cuando utilizó su forma en un proyecto urbanístico - fol. 217v-. La producción de Leonardo se conoce a través del encargo de Florimond Robertet, secretario de Estado del rey francés Luis XII en Milán en el año 1499, poco antes de abandonar la ciudad. En 1501 se encuentra la primera noticia que se refiere al artista trabajando en ella. Se trata de una carta dirigida a Isabella d'Este y firmada por Fra Pietro Novellara, quien hace especial énfasis en la novedad del huso cruciforme. Seis años después, el embajador francés recibe el encargo, ya en Blois. Al parecer, los inventarios de Salaì dan lugar a la posibilidad de que existieran dos versiones de esta obra. Una versión se habría enviado a Blois mientras que otra permaneció con Leonardo hasta su muerte, trasladándose, entonces, de Amboise a Milán. Poco más se supo de la fortuna de los encargos y las obras en los siglos siguientes. Parecería, pues, que la historia de este prototipo presagia la del Salvator Mundi: se conocía que Leonardo había trabajado en el motivo, pero no se conservaban obras del artista - aunque sí algunas copias y versiones de su escuela-. De las copias que circulaban de la Madonna dei fusi, dos eran consideradas obras maestras y sucesivas investigaciones han acabado por asociarlas con Leonardo da Vinci; una forma parte de una colección privada y otra, propiedad del duque de Buccleuch, está ahora expuesta en la National Gallery of Scotland. Fue esta segunda versión la que sufrió el robo durante el verano de 2003 en el castillo de Drumlanrig, propiedad familiar del duque. No fue recuperada hasta octubre de 2007 por las autoridades policiales escocesas. Anteriormente, Kemp había comisariado una exposición alrededor de estas dos versiones en la National Gallery of Scotland en 1992. Antes, había sido núcleo de la exposición Leonardo dopo Milano. La Madonna dei Fusi (1501) en Vinci en el año 1982, la cual versaba sobre la producción de Leonardo después de su residencia milanesa. Para profundizar en lo anterior, ver sendos catálogos. 
tos años de diferencia. Mediante un uso casi cinematográfico de la historia y la escritura, el robo se convierte en coartada para dilucidar los complejos procesos de autentificación a los que habitualmente son sometidas las obras de Leonardo.

Otro tema recuperado es el expuesto en los capítulos quinto y sexto: la historia de la atribución del retrato de Bianca Sforza llamado La Bella Principessa. A medio camino entre pintura y dibujo, la aparición de la obra y la repercusión de los sucesos posteriores dieron como fruto su exposición en la Villa Reale de Monza en 2015. Para la ocasión se presentó un catálogo coordinado por Kemp y con prólogo de Vittorio Sgarbi, ${ }^{14}$ aunque el historiador inglés ya había publicado sus impresiones en 2010 en el libro La Bella Principessa: The Story of the New Masterpiece by Leonardo da Vinci(ilustración 5$) \cdot{ }^{15}$ La historia del reconocimiento de la obra da pie a proponer un debate abierto acerca del confuso mundo del coleccionismo, las subastas y el valor y la honradez en el mundo del arte. Afortunadamente, más allá de recordar la historia del retrato de la supuesta princesa, el lector puede recrearse con la exposición del método científico de Kemp en el campo de las atribu-

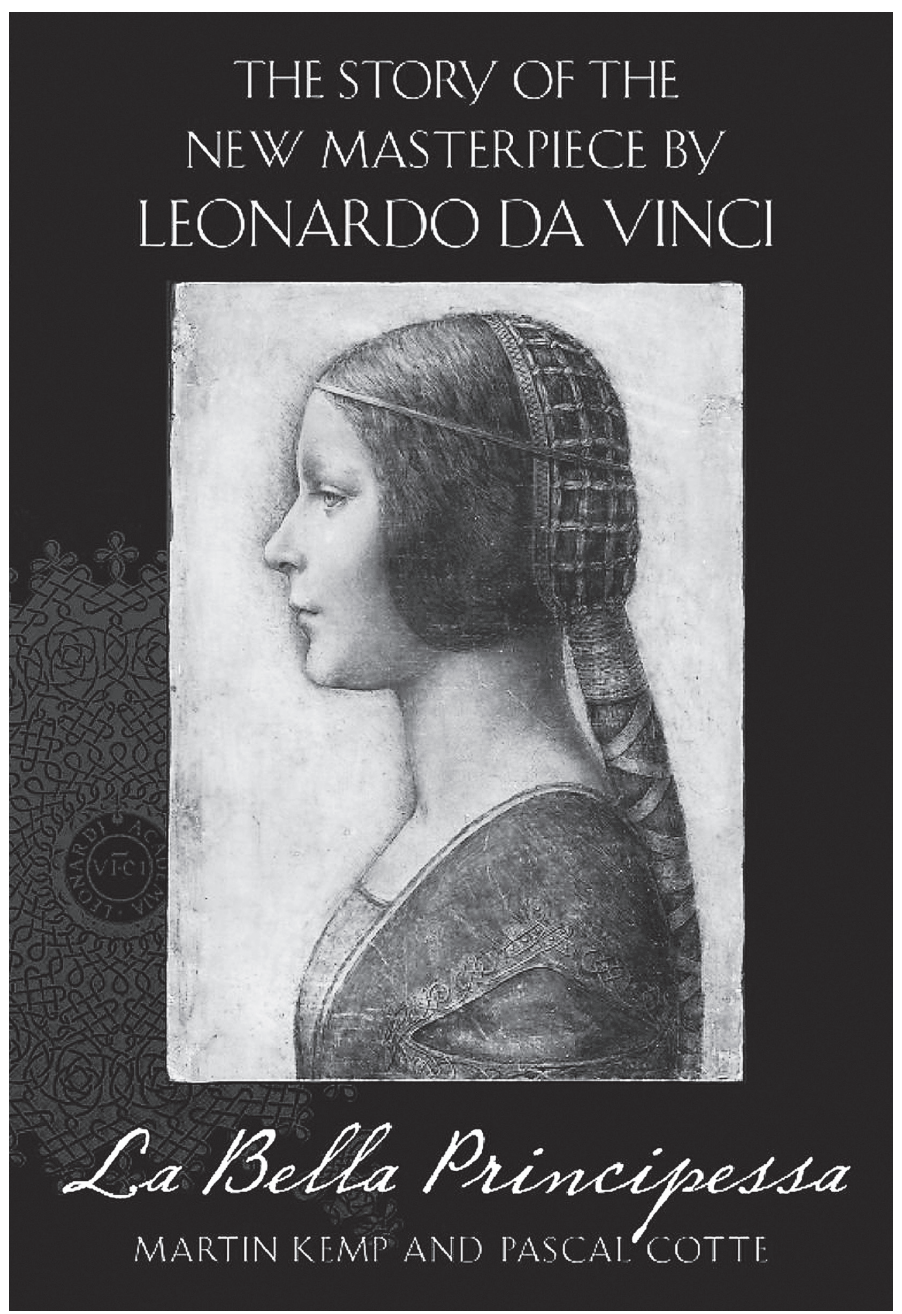
ciones. Conocimiento que desarrolla en no pocas ocasiones y que esporádicamente acom-

paña de cartas donde se exponen las argumentaciones del resto de los involucrados. Sobre el tema del método científico, Kemp volverá más adelante al mostrar una gran preocupación por lo que él considera uno de los principales problemas de la historia del arte: el de definir y homogeneizar el papel de la ciencia. El capítulo finaliza con una declaración personal: el mundo de las atribuciones está plagado de polémicas e intereses peligrosos que distorsionan la investigación histórica estricta. Por ello decide que su participación en estos últimos procesos ha tenido un último ejemplo con el caso de La Bella Principessa (ilustración 6). ${ }^{16}$

En cuanto a la cuestión de las atribuciones, no sabemos si la aparición de la que podría ser la primera creación de Leonardo da Vinci le llevará a publicar algo nuevo, pero por el con-

5. Martin Kemp y Pascal Cotte La Bella Principessa: The Story of the New Masterpiece by Leonardo da Vinci. Londres: Hodder \& Stoughton, 2010, portada.

14. Vittorio Sgarbi es un perfil de escritor con una disposición, seriedad y compromiso distantes a los de Martin Kemp y Carlo Pedretti. Polémico, multifacético y siempre omnipresente en el aparato mediático, ha combinado una prolífica y cuestionable carrera política con la crítica, el comisariado de arte y la participación en la tertulia televisiva. Su nombre se acompaña habitualmente de serias acusaciones de estafa y falsedad documental, además de plagio, como ocurrió con su texto introductorio a la monografía de Sandro Botticelli: SGARBI, V., «L'estenuata eleganza di Sandro Botticelli», en BASTA, C., Sandro Botticelli. Italia: Skira, 2007. Sobre la noticia del plagio véase ERBANI, F., «Sgarbi e il plagio su Botticelli», La Repubblica, 2 de diciembre de 2018, disponible en http://ricerca.repubblica.it/repubblica/archivio/repubblica/2008/12/02/ sgarbi-il-plagio-su-botticelli.html [fecha de consulta: 23 de junio de 2018]. Su actividad como comisario de exposiciones le ha llevado a presentar gran cantidad de muestras de arte italiano en época moderna, a actuar como curador del pabellón italiano en la $54 .{ }^{\text {a }}$ Bienal de Venecia y a fundar el proyecto Museo della Follia, un espacio expositivo itinerante.

15. Kemp, M.; CotTe, P., La Bella Principessa: The Story of the New Masterpiece by Leonardo da Vinci. Londres: Hodder \& Stoughton, 2010 .

16. KемP, M., «The Beautiful Princess», en idem, Living with Leonardo..., págs. 136-157. 

look intensively before using magnifying glasses and comparing with digital images. Looking past the obvious restorations - rather like filtering out the scratchy noises on an old music recording - I could see that the image sang with a refined beauty. It exuded an intimate sense of the sitter's living presence. It was poignant to gaze at the quiet and formalized effigy of a tender young woman, little more than a girl, already locked into her predetermined role - an aristocratic role constrained by social niceties. Likely to be married at the age of thirteen or fourteen, she was destined to be a trophy in a rich man's cabinet. Whoever she was, she might not live long.

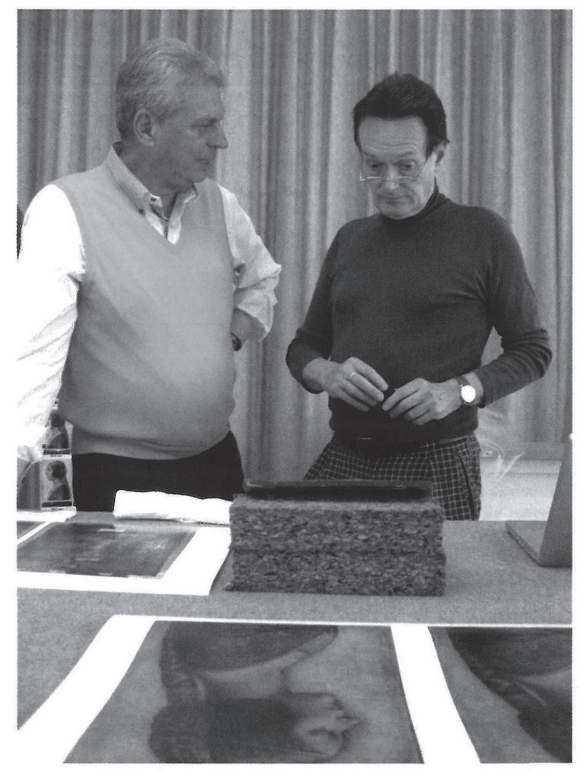

6. Martin Kemp Living with Leonardo. Fifty Years of Sanity and Insanity in the Art World and Beyond. Londres: Thames \& Hudson, 2018, pág. 149 .

\section{THE BEAUTIFUL PRINCESS}

We spent a long time looking, mainly without talking. It is wise to

Silverman and Kemp: double scrutiny.

texto y los personajes que involucra, es probable que seamos testigos de un intenso intercambio de opiniones. Por el momento, él ya ha dicho que a su parecer se trata de un fraude. ${ }^{17}$ Para esta ocasión, el circo mediático cuenta con el protagonismo de Ernesto Solari, ya conocido por los expertos en Leonardo por su tendencia a las hipótesis herméticas, e Ivana Rosa Bonfantino. ${ }^{18}$ Ambos exhibieron, el 21 de junio de 2018 en Roma, una mayólica que supuestamente representa al arcángel Gabriel en su perfil izquierdo. La atribución a Leonardo se basa, en este caso, en el descubrimiento de la firma y fecha, para la que han debido de realizar numerosos estudios e interpretaciones grafológicas y que, por otro lado, es un hecho documental del que carecen el resto de sus obras.

Y aparece el Salvator Mundi, ahora en Abu Dhabi (ilustración 7). Penúltima polémica sobre Leonardo da Vinci y magistral apertura del siguiente capítulo. Cuenta Kemp que la noticia le llegó en marzo de 2008 de la mano de una invitación a ver la obra y discutir su atribución en la National Gallery londinense. La primera exploración formal y la agitación de ver en ella el mundo de Leonardo concluyen bruscamente en un arrebato por ocultar emoción y precipitación ante sus colegas. El de la emoción es un matiz que a lo largo del relato solo se había presentado en los ejercicios de retrospección, casi romántica, a los recuerdos de toda una vida. En el resto del libro, Kemp trata de afianzarse una imagen de seriedad y compostura académica. Por lo que concierne a la obra, más adelante el autor reconocerá haber tenido constancia de que podía relacionarse con Leonardo y lamenta no haberle prestado suficiente atención hasta ese momento. A partir de aquel encuentro se compromete a iniciar una investigación al respecto. ${ }^{19}$

17. Kennedy, M., «Leonardo's earliest surviving work? Self-portrait as Archangel Gabriel unveiled», The Guardian, 21 de junio de 2018, disponible en https://www.theguardian.com/artanddesign/2018/jun/21/leonardo-claim-tile-self-portraitas-archangel-gabriel-unveiled [fecha de consulta: 25 de junio de 2018]

18. Con la voluntad de llenar el aparente vacío en la producción escultórica del artista, Ernesto Solari comisarió la muestra Leonardo scultore - Horse and rider en el Institut Français de Milán a finales de 2016 (sin catálogo). El protagonismo giraba en torno a dos obras. La primera, Caballo y jinete, es un bronce, a partir de un molde realizado a la escultura de cera de Leonardo, que representa la imagen del gobernador francés del ducado de Milán y amigo del artista, Carlos II de Amboise. La escultura de cera puede fecharse entre 1508 y 1511, fue atribuida al artista por Carlo Pedretti en 1985 y publicado como tal en 1987. Véase PeDretTI, C., The drawings and miscellaneous papers of Leonardo da Vinci in the collection of Her Majesty the Queen at Windsor Castle, vol. 2, Horses and other animals. Londres: Johnson, 1987. La segunda obra, Testicciola di terra, supuesto retrato de Salaì, habría sido realizada hacia 1497-1499 y ha sido estudiada por Ernesto Solari. Véase Bicocco, A.M.; SolARI, E., Leonardo: La «testicciola» di terra. Paderno Dugnano: Colibri, 2015. Carlo Pedretti presenta a Solari como uno de tantos investigadores preocupados en consolidar la imagen de Leonardo como personaje esotérico. Aparece extensamente citado en el capítulo «La Cena del secolo» de Leonardo \& io, cuando Solari le traslada su inverosímil tesis sobre el menaje oculto en el Cenacolo. Martin Kemp no le hace mención.

19. Martin Kemp menciona la preparación de una nueva publicación junto con Robert Simon, antiguo propietario de la obra, y Margaret Dalivalle, exalumna de Kemp en Oxford y experta en colecciones inglesas: Dalivalle, M.; KemP, M.; 
La historia del Salvator Mundi era conocida pero, como advierte Kemp, hasta aquel momento no se había invertido un esfuerzo intenso y manifiesto para trazar su historia y fortuna. Que Leonardo realizó al menos un diseño sobre este tema lo evidencian, entre otros hechos, los dibujos y copias de sus alumnos y seguidores; dos dibujos preliminares para una imagen de Cristo datados $c .1504$ en la colección real inglesa; ${ }^{20}$ un grabado de Wenzel Hollar según Leonardo; y un inventario de Fontainebleau del año 1642 que menciona un Cristo de medio cuerpo entre las obras del artista. ${ }^{21}$ El Salvator Mun$d i$ se consideraba perdido y no se tiene noticia de su fortuna entre los siglos XVI y XIX. Sin embargo, su historia contemporánea se acelera a partir de 2005, cuando es comprado por el marchante Robert Simon. A partir de este momento, se llevó a cabo su estudio y restauración y, al considerar probada su autoría, se acordó presentarlo en la exposición Leonardo da Vinci: Painter at the Court of Milan, celebrada en Londres a finales de 2011. ${ }^{22}$ Pese al encendido debate en torno a su presentación y atribución, la obra fue vendida por 450 millones de dólares en 2017 y actualmente se encuentra en el Louvre

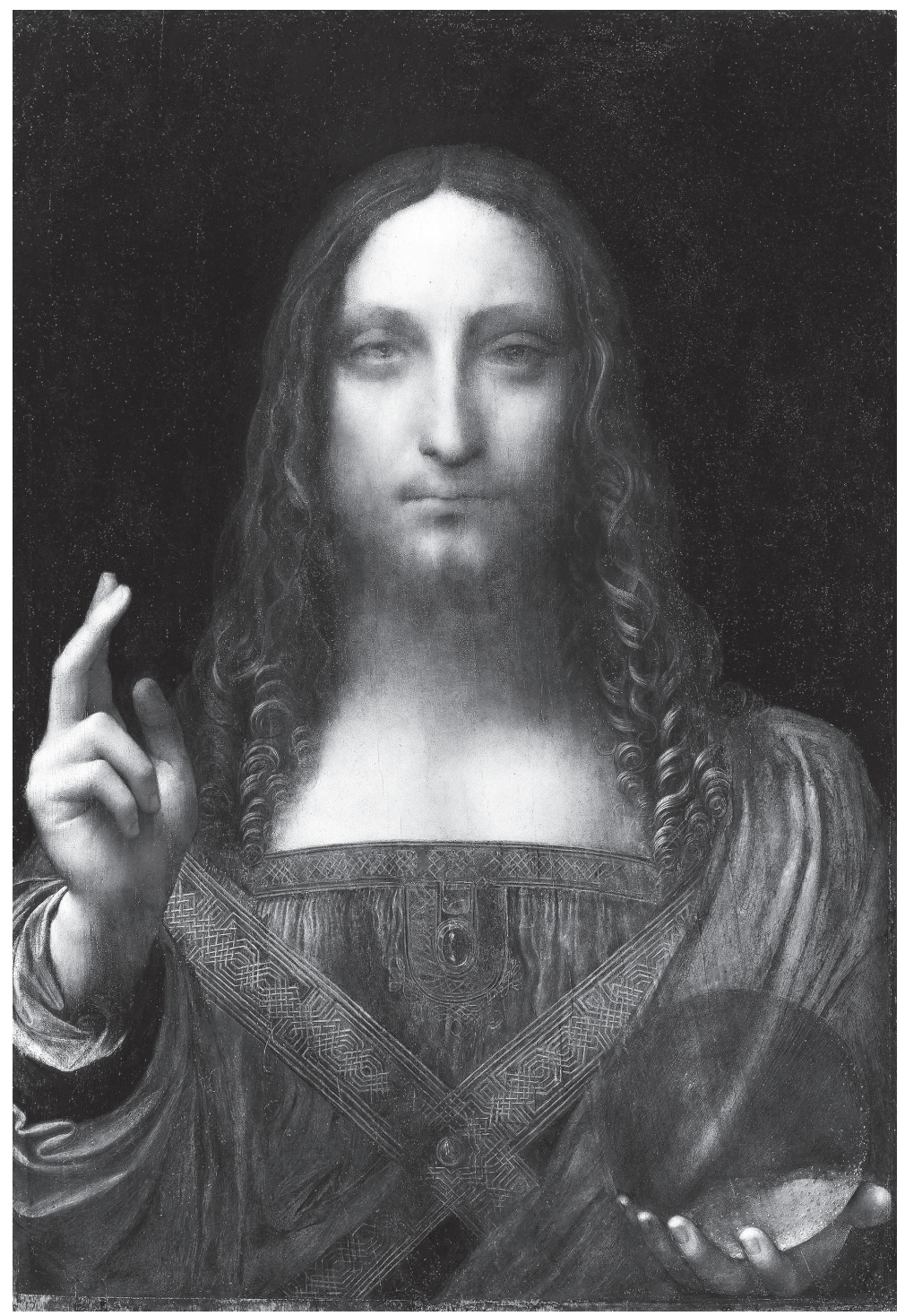

Simon, R., Leonardo's Salvator Mundi and the Collecting of Leonardo in the Stuart Courts. Oxford: Oxford University Press, 2018. La mención de Kemp se extrae de: KeMP, M., Living with Leonardo..., pág. 209.

20. Véanse las fichas 89 y 90 de Luke Syson para el catálogo de Londres de 2012. También las fichas 40 y 41 en NATHAN, J.;Z̈̈LlNER, F., Leonardo da Vinci. 1452-1519. Obra gráfica. Barcelona: Taschen, 2017, págs. 6o y 61. Igualmente mencionados en PEDRETTI, C., Leonardo \& io..., pág. 531. Anteriores publicaciones de referencia, como la monografía sobre los dibujos de Windsor, realizada por Kenneth Clark y revisada por Pedretti, se refiere a ellos así: «a study for the left arm, raised in blessing, of a globe-bearing Christ which is lost, but known to us from an engraving by Hollar dated 1650 [...] and other replicas less close to the original, e.g. in the Vittadini and Cook Collections. Leonardo is known to have received a commission for such a subject from Isabella d'Este on May 14 ${ }^{\text {th }}$, 1504». En CLARK, K.; PedretTI, C., The Drawings of Leonardo da Vinci in the Collection of Her Majesty the Queen at Windsor Castle, 3 vols. Londres: Phaidon, 1968, vol. 1, pág. 94. Los dibujos están reproducidos en el vol. 2, láminas 12524 y 12525.

21. «[...] de cét excellent peintre il y a cinq Tableaux en ce Cabinet. [...] Le troisiéme est un CHRIST à demy corps», en DAN, P., Le trésor des merveilles de la maison royale de Fontainebleau. Contenant la description de son antiquité, de sa fondation, de ses bastimens, de ses rares peintures, tableaux, emblemes, \& devises... París: Sébastien Cramoisy, 1642, disponible en https:// gallica.bnf.fr/ark:/12148/bpt6k96507143 [fecha de consulta: 25 de junio de 2018].

22. Frank Zöllner, autor experto en Leonardo da Vinci, presenta una excelente ficha técnica en la monografía sobre Leonardo, obligatoriamente revisada para la edición de 2018 tras la presentación oficial y subasta de la obra. Según Zöllner, el Salvator Mundi atribuido a Leonardo es una obra documentada en la colección de sir Francis Cook, quien la compró en 1900 de sir John Charles Robinson. El 25 de junio de 1958 la sede londinense de Sotheby's vendió la colección Cook y, por ende, el Salvator Mundi, que fue a parar a un propietario identificado como Kuntz. Se desconoce su paso a manos americanas, pero volvió a aparecer en 2005 como lote en una subasta en Luisiana. Robert Simon, historiador y reconocido marchante de arte, compró la obra por un valor relativamente bajo, al parecer alrededor de los 10.000 dólares, y se encargó de conducir su estudio y restauración - junto con Dianne Dweyer Modestini- antes de presentarla en el verano de 2011 en la exposición Leonardo da Vinci: Painter at the Court of Milan en la National Gallery de Londres. Los mejores estudios son

7. Leonardo da Vinci Salvator Mundi, c. 1507, óleo sobre tabla, $65,5 \times 45,1 \mathrm{~cm}$. Louvre Abu Dhabi, Abu Dhabi. 


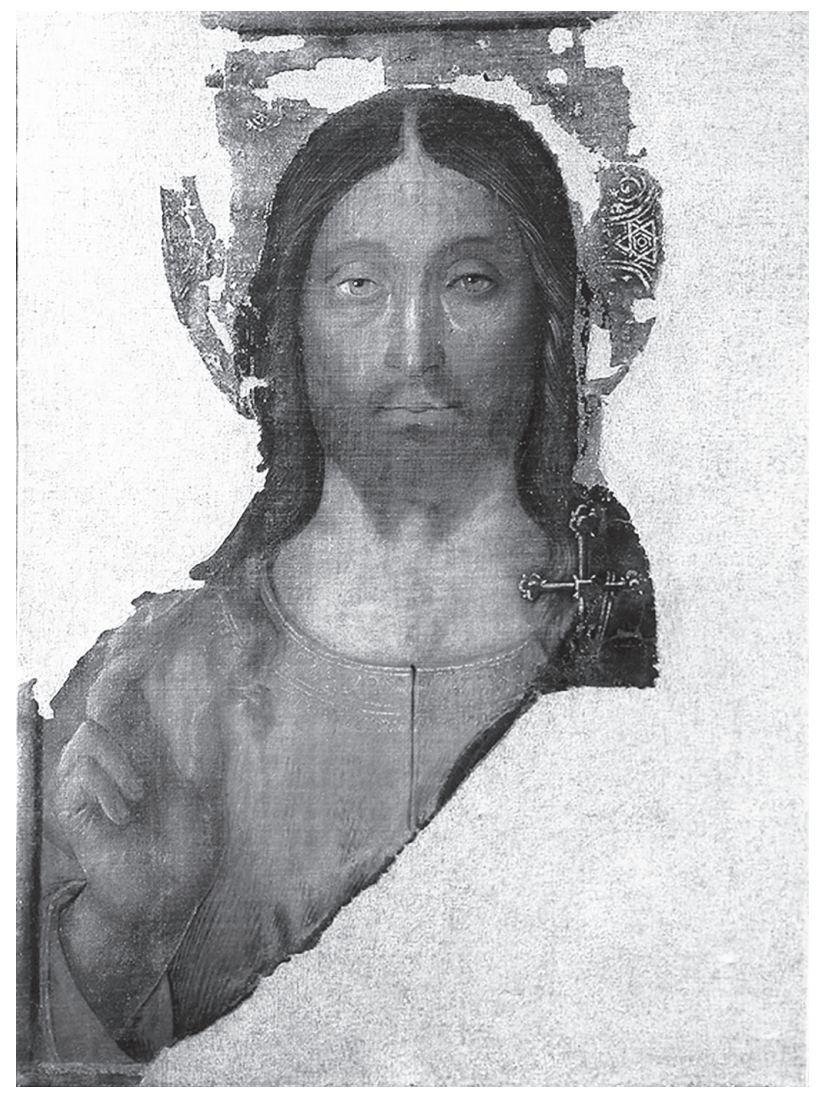

Abu Dhabi. Desde 1909 no aparecía un nuevo Leonardo con visos de verosimilitud, señala Kemp, así que era evidente que la obra iba a despertar todo tipo de debates y atención. ${ }^{23}$

Carlo Pedretti también había tratado el tema en Leonardo \& io, considerándola una obra perdida cuyo estudio habían concluido de forma notable Heydenreich y Snow-Smith a lo largo de las décadas de 1970 y 1980. Entre las copias de seguidores que ayudaron a trazarle un contexto destaca el Salvator Mundi de Béhague-Ganay, mejor versión de todas y para la que propuso una atribución a Girolamo Alibrandi con motivo de su exposición en Nápoles, sede permanente de la obra. ${ }^{24}$ En Leonardo \& io prevalece la opinión expresada en 1973 y que basa en los siguientes argumentos: existe un Cristo de medio cuerpo de Leonardo da Vinci que está perdido y que se conoce mediante un gran número de copias, de las cuales la más fiel podría ser la incisión de Hollar de 1650; el análisis formal y comparativo entre las copias, los dibujos preparatorios y las obras ya atribuidas a Leonardo, conduce a situar su factura entre 1510 y 1515; en esta fecha, Leonardo habría coincidido con Isabella d'Este en Roma, quien años atrás le había pedido una obra con este tema, a la que el ar-

8. Melozzo da Forlì Salvator Mundi, 1480-1482, óleo sobre tabla, $54 \times 40,5 \mathrm{~cm}$. Galleria Nazionale delle Marche, Urbino. tista se había resistido, pero que bien podría haberle llevado a realizar algunos estudios preliminares. ${ }^{25}$ Posteriormente, amplía su argumentación en diversas ocasiones pero no se retracta

HeYdenreich, L.H., «Leonardo's “Salvator Mundi”», Raccolta Vinciana, 20, 1964, págs. 83-109; SNOW-SMITH, J., «The "Salvator Mundi" of Leonardo da Vinci», Arte Lombarda, 50, 1978, págs. 69-81; Modestini, D.D., «The "Salvator Mundi” by Leonardo da Vinci rediscovered: history, technique and condition", en MENU, M. (ed.), Leonardo da Vinci's technical practice: paintings, drawings and influence. París: Hermann, 2014, págs. 139-152; y Luke Syson para el catálogo de Londres de 2012, págs. 300-303. La datación se propone a partir de los dibujos preliminares de 1500 y el posible encuentro de un Salvator Mundi de Melozzo da Forlì que Leonardo pudo haber visto en Urbino a partir de 1502 y que le habría servido como inspiración y orientación debido a sus similitudes formales (ilustración 8). Mientras que Luke Syson apuesta por fechar la obra «de 1499 en adelante», Zöllner propone «después de 1507». Véase ZöLLNER, F., «Prólogo de la edición revisada de 2018», en NATHAN, J.; ZöLlneR, F., Leonardo da Vinci. Obra pictórica..., págs. 6-17. La ficha técnica, XXXII, se encuentra en las págs. $250-251$.

23. Se trata de la Madonna Benois. A principios de 1478 Leonardo da Vinci se establece por su cuenta en Florencia y menciona que está trabajando en el motivo de la Madonna, en concreto en dos imágenes devocionales. Es comúnmente aceptado que de este hecho surgieran más de dos proyectos y que, con el tiempo, al menos uno de ellos se convirtiera en la Madonna Benois. Es probable, también, que la llevara consigo a Milán, donde podría haberla finalizado. La falta de documentación hace necesario considerarla perdida hasta principios del siglo Xx, cuando aparece en una colección rusa. La familia Benois, propietaria de la obra, la exhibió en San Petersburgo en 1908, y en 1914 entró a formar parte de la colección del Hermitage. Allí, el conservador de pintura Ernst Friedrich von Liphart la atribuyó a Leonardo da Vinci. En el año 1984 fue expuesta en la Galleria degli Uffizi de Florencia, en cuyo catálogo participó Carlo Pedretti. El museo ruso también expone la Madonna Litta, algo posterior, perteneciente al ambiente milanés y cuya atribución ha sido ampliamente discutida en favor de la escuela de Leonardo. En este caso, la obra fue comprada por el museo a Antonio Litta, milanés, en 1865. Véase Kustodieva, T.K., Italian Painting: Thirteenth to Sixteenth Centuries. San Petersburgo: State Hermitage Museum, 1994. Sobre la mención de Leonardo acerca de su trabajo véase VILLATA, E., Leonardo da Vinci: I documenti e le testimonianze contemporanee. Milán: Ente Raccolta Vinciana, 1999, pág. 11.

24. La obra se presentó en el Museo Diocesano de Nápoles en una muestra ideada por Carlo Pedretti y titulada Leonardo a Donnaregina. I Salvator Mundi per Napoli en 2017. La obra formaba parte de la colección parisina de la condesa Béhague, posteriormente heredada por los marqueses de Ganay, de la misma ciudad. Una antigua alumna de Pedretti, Joanne Snow-Smith, la había atribuido a Leonardo en su estudio de 1978 y, aunque se ha rechazado tal atribución, muchos estudiosos sí coinciden en que se trata de la versión más cercana a Leonardo, con lo que Pedretti no escatima en citarlos: Bora, G., I disegni del Codice Resta. Milán: Silvana, 1978; MARANI, P.C., Leonardo: catalogo completo dei dipinti. Florencia: Cantini, 1989.

25. Véase Pedretti, C., Leonardo: a Study in Chronology and Style. Londres: Thames \& Hudson, 1973. En el desarrollo de su argumentación, la relación con el Salvator Mundi de Melozzo da Forlì sigue presente en tanto que posible modelo 
de lo más sustancial y considera que todo el alboroto del Salvator Mundi es parte de una sofisticada operación de mercadotecnia cuyo objetivo final es la exposición londinense. ${ }^{26}$ Considera que la falta de pruebas y evidencias científicas refuerzan su hipótesis y finaliza su argumentación de forma solemne con una sentencia que viene a decir que la obra no puede ser de Leonardo y que «basta con mirarla».

A pesar de todo, Pedretti parece quedarse solo en su opinión. La mayor parte de los expertos consideran que la calidad del Salvator Mundi es indiscutible y que el dibujo recuerda a Leonardo sin ninguna duda, de lo que deducen que es más que probable que estuviese implicado en su ejecución; sin embargo, la atribución de la totalidad sigue resultando problemática. ${ }^{27}$ En suma, el capítulo «Salvator Mundi» de Kemp escenifica la reflexión acerca de cómo de importante es el comportamiento del propietario de una obra — sus objetivos personales y para con ella-, cómo llega la noticia al dominio público, en qué espacio debuta -comercial, privado o público- y revela, una vez más, las entrañas, no ya de la obra que habla por sí sola, sino del mundo de los historiadores y el mercado.

El resto de los capítulos desarrollan sus preocupaciones alrededor de la ya anunciada y necesaria revalorización de la ciencia en el arte; el papel de la mirada y la construcción de argumentos en la interpretación de la obra; la continua revisión de planteamientos en torno a la vida y obra de Leonardo da Vinci; la veracidad en el discurso en oposición a lo falso y pobremente fundamentado y los beneficios y perjuicios provocados por fenómenos mediáticos, cuyo caso paradigmático es la novela El código Da Vinci de Dan Brown. No obstante tratarse de un relato insustancial, dice Kemp, le ayudó a vender sus libros. ${ }^{28}$ Una cuestión singular de este episodio es la aversión que al historiador inglés le provocan las teorías de composiciones geométricas con significado simbólico, cuestión que no mucho tiempo atrás había pertenecido al discurso académico, como bien hace notar refiriéndose a cierto profesor y universidad.

El autor concluye su obra con una reflexión y un consejo. La reflexión desvela que detrás de Leonardo da Vinci se halla un apetito insaciable por entender y reproducir las leyes de la naturaleza, nada menos, pero tampoco nada más. El consejo sugiere: para tratar de entender a Leonardo no hay mejor ejercicio que recurrir a él, leer sus escritos y mirar sus dibujos y pinturas, no existe mayor fuente de información: lo mejor de Leonardo es el propio Leonardo.

e inspiración, pero en este caso la obra no aparece atribuida a Melozzo da Forlì sino a Bramantino: PedRetTI, C., Leonardo \& io..., pág. 531. También menciona que durante años se atribuyó a Leonardo un Salvator Mundi expuesto en la National Gallery de Londres y que posteriormente se ha reivindicado para Bernardino Luini. Sobre el encargo de Isabella d'Este, mencionado por diversos investigadores, véase Luzzıo, A., I precettori d'Isabella d'Este. Ancona: A. Gustavo Morelli, 1887, así como, del mismo autor, «Nuovi documenti. Ancora Leonardo da Vinci e Isabella d'Este», Archivio Storico dell'Arte, 1, 1888, fasc. III, págs. 181-184, disponible en http://digi.ub.uni-heidelberg.de/diglit/archivio_storico_arte1888/o275/image [fecha de consulta: 26 de junio de 2018].

26. Pedretti, C., «Il “Christo giovenetto” di Isabella d'Este», L'Osservatore Romano, 6 de mayo de 2010; idem, «Diavolo di un aiutante», L'Osservatore Romano, 13 de marzo de 2010; idem, «Se Leonardo è una chimera», L'Osservatore Romano, 12 de julio de 2011. Citados en Pedretti, C.; Barbatelli, N., Leonardo a Donnaregina..., págs. 33-35.

27. Tres dudas hay al respecto. Primero: no es mencionado en fuentes antiguas, mientras que las mismas sí se lamentan de su poca producción. Asimismo, un Salvator Mundi aparece en un inventario de 1525 pero como obra de un discípulo. Segundo: su restauración no está documentada. De hecho, Zöllner vacila en el inicio de su fecha, que finalmente sitúa entre 2005 y prolonga hasta 2017. Se ha anunciado una publicación sobre su restauración, pero esta sigue sin aparecer. A la falta de información se suma el hecho de que las imágenes que se han distribuido de la obra desde 2011 muestran modificaciones y alteraciones en la misma. Tercero: la datación consensuada de $c .1499$ no concuerda con otras obras y dibujos de los que parece que es fruto y que tienen fecha posterior. Véase ZöLlNER, F., «Prólogo de la edición revisada...», págs. 6-17.

28. Dan Brown también aparece en Leonardo \& io, aunque su autor confiesa no haberlo leído con atención. Por cuanto respecta a la afiliación de Leonardo con la sociedad secreta del Priorato de Sion - argumento que Dan Brown tomó del libro The Holy Blood and the Holy Grail-, Pedretti se comprometió a realizar una investigación que pudiera demostrar algo al respecto, pero los resultados fueron nulos. En PedretTI, C., «Una crociera per esordio», Leonardo \& io..., págs. 16-19. En la conclusión del capítulo, Pedretti cita a Leonardo de forma magistral apoyándose en la opinión que el artista trazó en el verso del folio 19045, dentro de la colección real inglesa, sobre las serias consecuencias de mentiras, bulos y conspiraciones: «più meriterebbero [questa generazione] se non fussino stati inventori di cose nocive come veneni e altri simile ruine di vita e di mente». En Clark, K.; Pedretti, C., The Drawings of Leonardo..., vol. 3, pág. 21 -ficha-y lámina 19045 - dibujo-. La cita se ha tomado de PedretTI, C., Leonardo \& io..., pág. 21. 
Así acaba, pues, la publicación de 2018, una obra conmemorativa de la fortuna de Leonardo da Vinci que supone una especie de conclusión en la relación entre ambos protagonistas: creador e historiador. A diferencia de la publicación de 1981, en la que Kemp exponía la vida intelectual del artista y presentaba al genio en unidad, el lector tiene en esta ocasión una obra compuesta de episodios fracturados, heterogéneos, de acuerdo con los procesos historiográficos posmodernos. Si años atrás lo sugestivo era mostrar la visión que Leonardo tenía del mundo, ahora el mismo autor nos muestra lo contrario, cómo el mundo ha recibido y tratado a Leonardo pasando de un reflejo del mundo a una idea de lo exterior que devuelve una imagen del mundo profesional y académico. La antigua obsesión de Martin Kemp por conseguir un equilibrio en el retrato del artista está lejos de la cualidad informativa de esta obra, y las hipótesis que ha desarrollado a lo largo de su carrera se convierten ahora en recursos que rescata a modo de recuerdos o de argumentos de soporte del texto. Pero como había puesto de manifiesto en el prefacio a la reedición de The Marvelous Works, «Cada obra pertenece a su tiempo y lugar, como bien me percaté al leer la mía». Y así es; los que conozcan al autor sentirán que, de la proyección hacia un público académico y la integridad de una monografía, Martin Kemp se ha trasladado al mundo de la conmemoración y el homenaje, ámbito acorde con un público más amplio que demanda recreación más que creación.

El autor se ha expuesto ante el lector explicitando su posicionamiento ético y académico, así como su personalidad, por medio de los contextos a los que su trabajo le ha llevado: personajes, paisajes, ciudades, viajes, exposiciones, etcétera. Como verá el lector, Kemp es protagonista en cada uno de los capítulos no solo a través de sus vivencias personales y, por lo tanto, por ser fuente primaria de ellas, sino por parangonarse con sus otros protagonistas y, a un nivel más profundo, con el propio Leonardo. La relación entre Leonardo y Martin ha traspasado el terreno científico de anteriores publicaciones para situarse definitivamente en el personal y emocional. Circunstancia previsible para un hombre que ha dedicado su vida al estudio de un genio y que ha demostrado haber cumplido con minuciosidad la misión del historiador de honrar la vida y obra de aquel con la estricta verdad. Esta nueva relación entre ambos, basada en la proyección del historiador en el artista, ocurre y se revela de forma inevitable y restringida, y eso es algo que tiene que ver con su longeva relación pero, sobre todo, con la capacidad del historiador - al respecto podríamos añadir también el caso de Carlo Pedretti- y la genialidad del artista. El Leonardo adulto, pintor de paisajes, aparece a través de Martin Kemp al deleitarse relajado con el panorama de la Toscana; en Carlo Pedretti resuena el eco de otro Leonardo, el astuto y brillante joven que se apodera del historiador en su infancia cautivándolo mediante la intriga y el juego y que aparece en Leonardo \& io cuando Pedretti intenta confundir al lector, como si se tratara de usar la escritura especular.

Si la presente es una publicación idónea o capaz de hacer recordar a Leonardo da Vinci en el centenario de su fallecimiento - io es a Kemp a quien se quiere recordar? - se deja a juicio del lector, pero baste decir que desde el prólogo se advierte que parte de su contenido fue explotado con anterioridad en otros soportes, quizá mejores para tales historias, a lo que se suma, en un ejercicio de autoconfesión, la idea de la publicación como un legado de su prolongada e intensa experiencia con Leonardo; además de manifestar que el conocimiento es algo que se debe compartir más allá del mundo académico. Relativo interés, pues, para aquellos que busquen nuevas hipótesis, cronologías o ideas innovadoras. Dado lo anterior parece evidente que Living with Leonardo. Fifty Years of Sanity and Insanity in the Art World and Beyond no llenará un hueco historiográfico en cuanto al artista, pero sí en cuanto al planteamiento del eterno problema del historiador consigo mismo y con la inevitable proyección en lo investigado. 